\title{
Disaster relief needs more research
}

John Rivers, of the London Technical Group*, argues that more research on disaster relief is needed if funds are to be used effectively

THE CrClone and tidal wave that struck Andhra Pradesh in November last year killed about 30,000 people. But it devasted half a million, and made 2,000,000 more homeless. In the previous two years cyclones had also struck the state, ruining the harvest and leaving farmers deeply in debt. So, at the start of 1978, Andhra Pradesh is poised between recovery and a collapse that would make it rank alongside Sahel and Ethiopia in the vocabulary of suffering.

The immensity of this disaster has not, however, been reflected in the interest shown in it by the rest of the world. It has been a minor story, a few column inches on an inside page, while UK headlines have concentrated on the firemen's strike and the value of the dollar. Few seem to care about Andhra Pradesh. USAID figures, issued one week after the cyclone, estimated that aid from the international community was less than $1 \%$ of the $\$ 675,000,000$ of damage done. In Britain, the Disaster Emergency Committee's Appeal was a flop, raising only a quarter of the desired million pounds.

The public's lack of interest may not be surprising. The media have produced an unending diet of catastrophe. And the public may be becoming cynical about the usefulness of aid. This would be understandable, given such misdirected aid as the sending of skis to flood victims or brassieres to the starving, which rightly get pilloried in the press. But though newsworthy such events are of minor importance. The major waste in relief funds is more subtle.

In the rare cases where disaster research has been undertaken, the research has exposed the mythological basis of traditional relief. Inoculation campaigns, for example, have been an expensive component in all flood relief programmes since the war, as they were in Andhra Pradesh. Yet epidemiological studies by the Centre for Disease Control, Atlanta, Georgia, have revealed them to be unnecessary and ineffective. The vaccines are not as efficient as is often supposed, and they take about 10 days and two or more inoculations to give a reasonable level of immunity. Moreover the dilution of sources of contamination is much greater, and disruption of water supplies much less in disasters than has hitherto been supposed. So the alternative of simple symptom-reporting systems and intensive investigation of supposed outbreaks, is, as the Guatemalan experience has shown (Romero, A. B., Cóbar, R., Western, K. A. \& López, S. M., Disasters 2, 19-26; 1978) cheaper and more efficient than the fabulously expensive vaccination campaigns that hypnotise relief agencies. The money wasted on such unnecessary flummery is unlikely to have saved lives in Andhra Pradesh; almost certainly it cost lives by diverting scarce resources from more useful action. Other examples of such re-evaluation could be cited, even more await study. As long as disaster aid is less than adequate there will be a need for a science of relief, for a disaster technology.

In the days following the Bengal cyclone in 1971, the London Technical Group (LTG) was started by a group of postgraduate students anxious to encourage the growth of this field. Our first inclination was to initiate a dialogue between aid administrators and academic scientists. It was a twofold failure. First, most academic scientists had a crucial problem in their lack of practical experience of disaster situations. Scientific expertise, no matter how exalted, could be proved inappropriate by peculiarities, often social, of the population affected by the disaster. Food aid, for example, is a fairly unchallenged item of disaster relief, being sent on the premise that if infantile malnutrition is endemic in good times, it must reach horrific proportions following a disaster. In Andhra Pradesh, as in the Bengal Cyclone, this is unlikely: the sea surge itself killed the very young and the very old, so that the malnourished and vulnerable died, and only the fittest survived. The aid sent presupposed high levels of infantile malnutrition; they are probably lower than ever before.

In housing too the social factor can negate apparently good logic, and the whole field of disaster shelter is littered with clever designs that nobody wants as homes. There is a considerable body of evidence that the best choice for disaster shelter is to use local materials and local labour to rebuild. The result is acceptable, familiar, and morale boosting (Davies, I, Disasters 1, 82-90; 1977). Most architects and designers, however, seem to be unaware of these constraints, and find ready sponsors for their designs in government and charitable disaster relief agencies.

This pattern is repeating itself in Andhra Pradesh where the state government and some voluntary agencies are erecting pre-stressed concrete buildings ill-suited to the climate but enough of a status symbol to lead to consumer resistance against the modifications of traditional buildings that are being offered by other agencies. This indeed is typical of the second reason for LTG's failure:-the unwillingness of voluntary agencies and governments to accept scientific evidence, where this points to the need for a change in accepted practice.

In view of this failure it became apparent that if scientists are to contribute to disaster research, there must be a reassessment of the roles they play.

- First, acknowledging the limitations of the individual expert advisor, we should set out to develop multidisciplinary groups who can meld their individual talents into a new discipline of disaster research. UNESCO already has its earthquake team which visits the site of earthquakes for seismic research. There is no reason why analogous teams, independent of aid donors, should not be formed to investigate the social and medical impact of natural disasters. Research into the effectiveness of disaster aid could be immediately undertaken if only the aid agencies would agree to fund it. It would provide valuable evidence about any need for change in aid policies. In time, if such research became routine, results would be available to relief agencies to direct aid in any current disaster, rather than on a retrospective basis.

- Second, there is a need for longer term investment in research into the nature of disasters themselves. There is much we need to know about disasters, and the social response to them. Scientists as yet may have only an impersonal understanding of disasters, but at least they do know how to ask questions.

As always with research the problem is one of money, and investment in a programme of disaster research requires an act of faith by some funding agency. Justification for such faith may be found in the surprising yield of results from the fragmentary funding the subject has received in the UK and USA over the last 10 years -sufficient indeed to support two journals specialising in the field.

What can science achieve? Eloquent testimony exists in 'Maladie de Famine', a little known book of researches into the pathophysiology of famine which, although over 30 years old, is still the definitive work on the topic. It was a study conducted in the Warsaw Ghetto, by scientists, themselves victims of starvation and under sentence of death. No better memorial could be found to these men than to continue their work. 